\title{
A technology valuation model to support technology transfer negotiations
}

\section{Dong-Hyun Baek ${ }^{1}$, Wonsik Sul ${ }^{2}$, Kil-Pyo Hong ${ }^{3}$ and Hun $\mathrm{Kim}^{3}$}

\author{
${ }^{1}$ Department of Business Administration, Hanyang University, 1271 Sa-l dong, Sangnok-ku, \\ Ansan, Kyeonggi-do, 426-791, Korea. estarbaek@hanyang.ac.kr \\ ${ }^{2}$ Corresponding author: Division of Business Administration, Sookmyung Women's University, \\ Hyochangwongil 52, Yongsan-ku, Seoul, 140-742, Korea.wssul@sookmyung.ac.kr \\ ${ }^{3}$ Division of Business and Commerce, 115 Anseo-dong, Cheonan-city, Chungcheongnam-do, \\ 330-704, Korea.kphong@bu.ac.kr, hkim@bu.ac.kr
}

\begin{abstract}
The development and commercialization of advanced technologies will depend increasingly on efficient technology transfer and technology trading systems. This requires the development of technology markets or exchanges and hence a reliable technology valuation methodology. This paper develops a methodology for an objective and impartial valuation of fully developed technologies.
\end{abstract}

A web-based technology valuation system is developed with which interested users can make efficient and real-time evaluations of technologies.

\section{Introduction}

$\mathrm{I}_{\mathrm{i}}^{\mathrm{t}}$ $\mathrm{t}$ is an established notion that technology innovation plays a vital role in building national competitiveness, and every state and corporation is concentrating on fortifying their global competitiveness with high technology development capability that is difficult to imitate. In order to facilitate the advancement and development process of high technology, a market for technology transfer must be promoted. In Korea, to do this, Technology Transfer Committee was established in February 2000, along with Korea Technology Transfer Center and Certified Value Advisor in April and December of the same year, respectively, to provide institutional support for encouraging technology transfer.

Institutional support such as technology brokerage and exchange is necessary for active trade and transfer of technology, but information, especially reliable information on the value of technology is as important. The problem arises because information on technology cannot be provided like general goods, and, thus the role of a technology valuation as a complementary measure becomes very important. There is a special need to evaluate the value of a specific technology from an objective perspective in order to encourage technology transfer. As the market price is used for the basis on price negotiation in trading goods, an objective value of a specific technology must be presented in advance for the negotiation to be carried between buyers and sellers of technology.

Accordingly, much attention has been focused on evaluating the objective value of technology in Korea. Many organizations including Korea Institute of Industrial Technology Evaluation and 
Planning, Korea Institute of Science \& Technology Evaluation and Planning, and Korea Technology Credit Guarantee Fund have been using various valuation models to perform evaluations for aiding decisions regarding investment and putting up technology as collateral. Yet, it is difficult to promote technology trade and transfer with the usual valuation process that focuses on the technology itself. Valuation models thus far have assessed the value of technology from the perspective of the firm in possession of the technology, but such assessment is greatly influenced by the firm's technological capability, capitalization, brand, and human resources. However, what the market needs is the worth of technology as a product to be traded in the market, and this calls for an impartial and objective value that is not influenced by the specific company that owns it. But, as no appropriate valuation method has been proposed thus far, there is a need for a new way of appraisal.

The systems that encourage technology transfer can be classified into two in general: a simple system that just builds and offers data on the information about the technology to transfer and the other one that encourages technology transfer by making evaluations of technologies in various perspectives. One of the examples of the former is the Tech-Net run by SBA (Small Business Administration) of USA and the latter is ValueBased Modeling of Defense Diversification Agency in Britain and the TOP-Index system of National Technology Transfer Center in USA.

This paper's objective is the development of a technology valuation system that will support the development of technology valuation models and the valuation process according to those models with the intention of promoting technology trade and transfer. According to Simon's (1960) identification of different types of decision-making problems, assessing the value of technology can be seen as an unstructured problem. As no regulation or procedure for technology valuation exists, the decision-maker's judgment becomes absolutely influential. By applying the technology valuation model suggested by this research, however, this unstructured problem is converted into a semi-structured problem with some regulation and procedure. Yet, there still remains the difficulty of having to rely on the subjective judgment of the decision maker for estimation of diverse parameters used in the evaluation. The technology valuation system developed in this research will not only guide the assessment process, but will provide prompt information for each step in the process, enabling an objective and reliable appraisal with the use of as much objective information as possible in the estimation of parameters.

This paper is organized as follows. Section 2 introduces previous research on technology valuation. Section 3 introduces the technology valuation model presented by this research, while the explanation on the technology valuation system will be given in Section 4. Finally, Section 5 follows up with the conclusion.

\section{Concept of technology valuation and previous research}

\subsection{Concept of technology, value, and technology valuation}

Technology, which becomes the object of technology valuation, is divided into broad and narrow definition of technology. Narrow concept of technology refers to intellectual property including patent, utility model patent, and trademark in addition to disparate technology such as knowhow, trade secret, and computer software. Broad concept is not limited to individual technology, but covers the firm's total technological capability as well. Technology is valuable as an asset and is identified as an intangible asset. Intangible assets with technical basis are varied in character and include patent rights, trade secret, knowhow, computer software, database, and operations guide. Intellectual property alludes to those whose possession is recognized and protected by the law, and it is comprised of trademark, copyright, computer software, patent, industrial design, and trade secrets. Technologies that are not defined as intellectual properties are mostly those that are difficult to recognize or difficult to assess their value independent of the owner (company, individual), and it is rare for such technology to become the object of valuation.

Economically speaking, the value refers to the opportunity cost, which becomes the standard of the transaction, while the market price becomes the exchange value when a perfect market is assumed. However, as the market for technology cannot be created easily, a difficulty arises in determining the exchange value of technology through the market mechanism efficiently. Accordingly, additional effort in estimating the fair market value, supposing a competitive market, is required.

Generally, the fair market value is defined as 'the price at which willing parties, who have not 
been coerced and possess rational information, have agreed to trade their asset' (Seol, 2000). It is almost impossible, however, to come across such a perfect deal in reality, and, thus this value assumes a transaction between virtual buyer and seller. Particularly, it presupposes an economic or market condition occurring at a specific point of evaluation. Such fair market value is at times simply called the market value, and it assumes that the capital market is in its advanced stage where it remains in a nearly perfectly competitive form. The technology valuation attempts to estimate this market value.

Nonetheless, the content of technology valuation can vary in accordance with the perspective taken by the assessor. Seol (2000) suggested that technology valuation has four aspects, each with a different theoretical basis, while Lee's (2001) research proposed various concepts and methods of technology valuation, such as assessment of company's internal competence and technology forecast for analysing changing trends. From the viewpoint of government policy, these varying technology valuation methods exhibit a strong tendency to survey technology's environmental and socioeconomic impact, while assaying the side effect on the industry from the macroeconomic perspective. Also, while the manager of government research and development investment will find it necessary to set a priority on proposed technology development projects, the individual corporation will be interested in evaluating a technology for its economic efficiency. Various outlooks regarding technology valuation is organized in Figure 1.

With so many different perspectives on technology valuation, it is very challenging to present a generally applicable technology valuation model. The difficulty is attributed to the fact that the model, the range of its variables, and the measurement range for each variable are all affected by the intent of valuation. This research limits itself to technology valuation that is represented by the monetary, economic value of the firm and its business units.

\subsection{Previous research on technology valuation}

When valuing technology in order to evaluate its economic worth from a microscopic point of view, previous research have suggested cost approach methods, market approach methods, income approach methods, and real options as major valuation methods. First, the cost approach methods estimates the cost of recreating the future utility of the technology being valuated, and assumes this value to be the future returns from the technology (Smith and Parr, 2000). Technology assessment is done by calculating the reproduction cost of acquiring the same technology or the substitute cost of acquiring a similar asset, and then reflecting depreciation. The cost approach method is useful when assessing intangible assets such as software, but its weakness lies in that equal amount of investment does not always result in the same level of technology and that it does not take into account important elements such as future risks and economic benefits that can be obtained from the assets.

Secondly, a technology valuation model based on the market approach method estimates the market price of a similar technology that has already been traded on the market and applies it

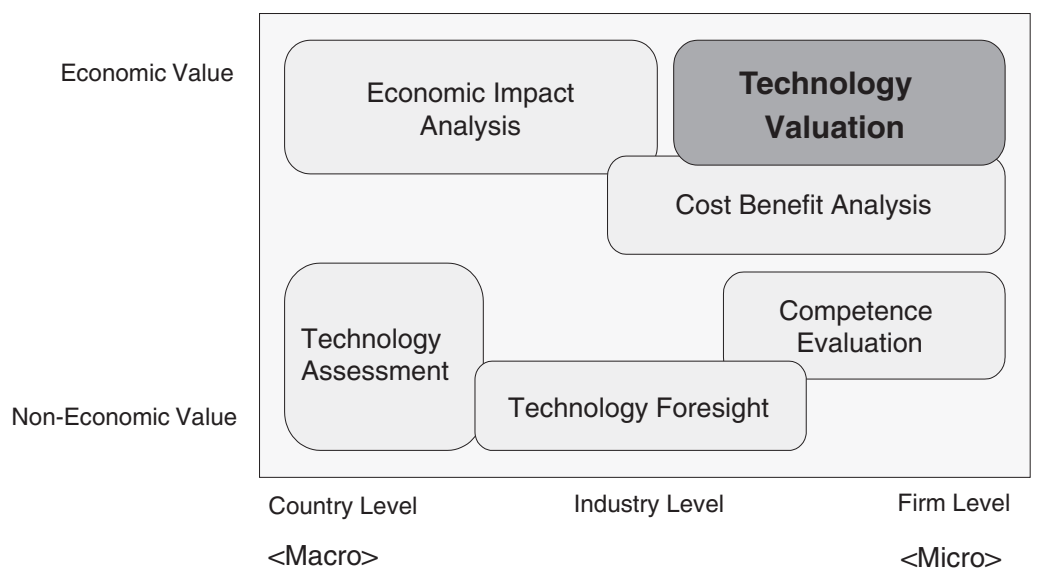

Figure 1. Various outlooks regarding technology valuation. 
to their assessment (Reilly and Schweihs, 1998). Generally, if there already exists a comparative market where assets are being actively traded, and if information on the transaction costs is readily available, it can become a practical method. In this sense, while it is effective for assessing real estate, vehicles, general purpose computer software, liquor license, and franchises, it is not effective for assessing the cases like most intangible assets or intellectual property, where similar instances of transactions are infrequent or the details of the transactions are not revealed.

Thirdly, the income approach method considers the sum of the present values of future cash flows of the technology as the value of the technology. This concept, disregarding the costs of technology development, determines the value of the technology according to its feasibility of creating expected profits (Boer, 1999). The income approach method is currently being subdivided into different branches according to its various facets surrounding the assessment of the future expected profit. These facets include the estimation of the income generation period, the estimation of future income, the risks of no profit, and the conversion of future earning into present value. Among these, the discounted cash flow method is the most widely used. The discounted cash flow first subtracts expenses from the cash flow received from the usage of assets, and then this net cash flow is adjusted at a proper discount rate. This method, while suitable for patents, registered trademarks, copyright, and other intellectual properties that can create a future profit, it has the disadvantage of being unable to accurately reflect the value of technology that does not create a direct profit but, nevertheless, bring value to the company, or technologies where future profits are hard to estimate.

The fourth method of real options incorporates the financial concept of options in technology valuation, and as options are not considered as an obligation but a right, the investors have the opportunity to correct their decision according to future environment (Copeland and Antikarov, 2001). Using real options in investment decisions such as research and development projects and technology transfer can guarantee flexibility against future uncertainty in decision making. Heo (2000) stated that real options is not simply a model that expresses the value of an option attached to an investment alternative, but that by itself is a complete valuation model of an investment alternative. The real options model does not need to rely on a subjective assessment of ex- pected returns, and while its benefit is that it recognizes uncertainty as an opportunity, its downside is the difficulty of applying the model to a real situation because of complexity of calculating important variables and the tacit acceptance of the rationality assumption (Hong et al., 2002).

Majority of the studies done already has chosen the most appropriate model out of the existing ones based on the goals and perspective of the evaluator. However, more and more attempts have been made to create an integrated model that combines individual and different models into one. For example, Boer's Technology Valuation Solutions focuses on how to integrate cash flow, decision tree, and real options approaches (Boer, 1999). As the goals, assumptions, and the approach of different models vary greatly, the technology valuator up till now had always ended up choosing the model that best suits his objective and perspective.

\section{Designing technology valuation model for promoting technology transfer}

This research aims to suggest a technology valuation model that is based on the income approach method and the real options and can express the objective value of a specific technology in economic terms (monetary amount). In so far as an objective value of a technology can become the starting point of a price negotiation between the buyer and the seller, technology transfer will be further promoted by having such a reference price.

The technology valuation model outlined by this research can be divided into three steps as can be seen in Figure 2. The expected returns analysis (Step I) utilizes product market and cost structure analysis according to different technology types in order to calculate the amount of profit that can be created during a specific period. The amount of profit is then converted into its present value based on the discounted cash flow model.

Technology contribution analysis (Step II) calculates technology's degree of contribution (technology contribution coefficient) to expected returns by taking into account the technology's level of innovation and the characteristics of the industry it belongs. The technology contribution coefficient is then corrected to reflect technology's dominance, exclusivity, and limitations. The expected returns from Step I is multiplied by the technology contribution coefficient in Step II to 


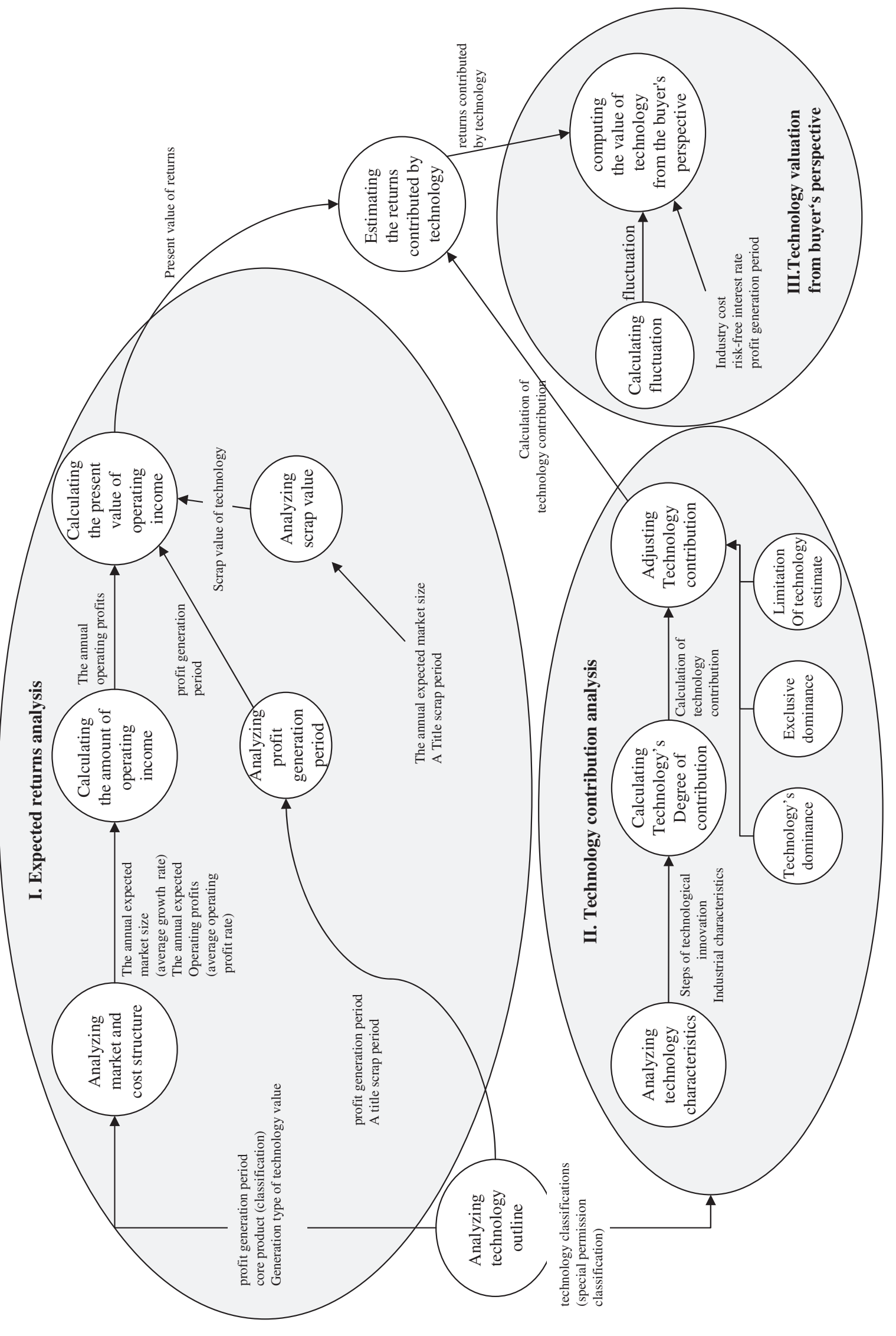




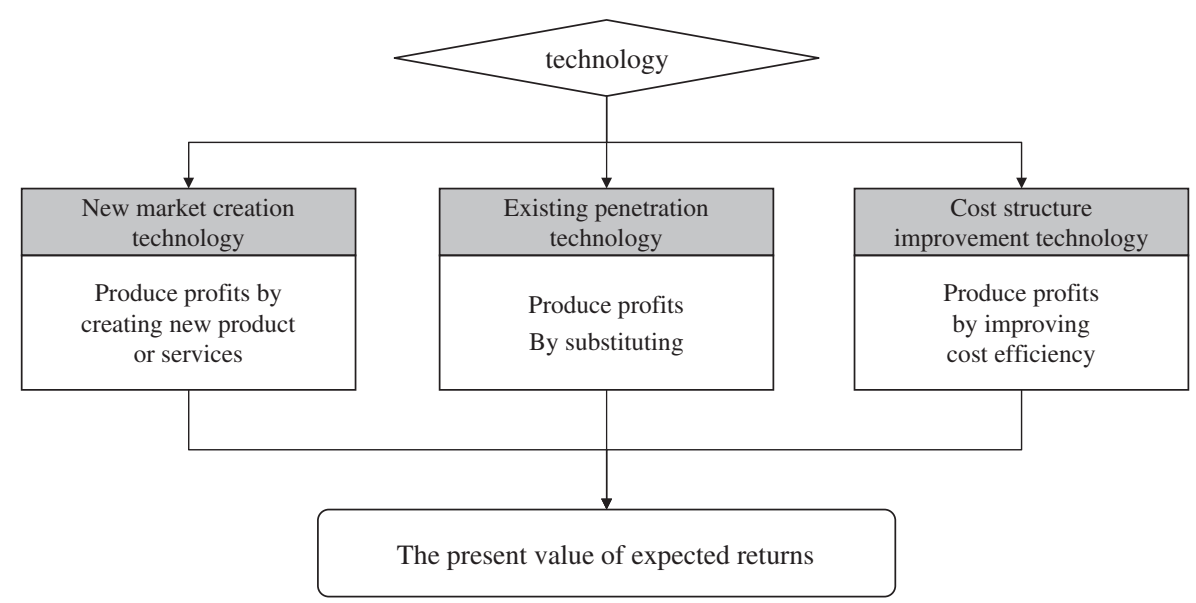

Figure 3. Classification of technologies.

produce returns contributed by technology, which is the objective value of a particular technology.

The technology valuation from the buyer's perspective (Step III) considers additional development costs, adjustment period and costs for commercialization, and dynamics of profit to assess the value of technology from the buyer's position. The decision on whether or not to purchase a particular technology depends on the comparison of this value to the returns contributed by technology calculated in Step II. Each step will be explained in detail in this chapter.

\subsection{Analysis of expected returns}

The first step of technology valuation is calculating the present value of expected returns from the technology. A classification of technologies must be made for this purpose. Figure 3 classifies technology into three types, and the new market creation technology and existing market penetration technology are product technologies that produce profits by creating new markets or by substituting existing ones. On the other hand, cost structure improvement technology is a manufacturing technology that does not increase the revenue or the size of the market, but it improves the profitability by altering the cost structure. Earlier studies have focused on product technology as it was more convenient to estimate their profits, but manufacturing technology is also an important object of technology valuation.

Expected returns from new market creation and existing market penetration technologies is calculated by projecting the time period during which surplus profits can be gained, estimating the amount of profit per year, and by adding the residual value of technology. In the case of cost structure improvement technology, it is possible to figure out the market size for the existing product, and thus, the only process required is approximating the rate of additional cost improvement from making use of new technology. Once the expected returns is calculated, it can be divided by appropriate discount rate to be converted into present value. The equation below is used to estimate the present value of expected returns.

$$
\begin{aligned}
N I= & \sum_{t=1}^{n} \frac{C F_{t}}{(1+r)^{t}}=\frac{C F_{1}}{(1+r)^{1}}+\frac{C F_{2}}{(1+r)^{2}} \\
& +\cdots+\frac{C F_{n}}{(1+r)^{n}}
\end{aligned}
$$

where $N I$ is the present value of expected returns, $C F_{t}$ the future cash flow and $r$ the discount rate.

\subsection{Analysis of technology's degree of contribution}

Technology's degree of contribution refers to percentage of profit that is purely attributable to technology itself. As there are many sources of profit increasing, and since they cannot be judged to be independent of each other, it is very difficult to extract the amount contributed by technology alone. Accordingly, this research model first defines the range of general degree of contribution, and then calculates the appropriate degree of contribution coefficient for individual technology, taking into account each technology's trait and the industrial characteristics.

As many previous studies and actual practice concerning technology valuation have estimated the proportion of contribution of technological 


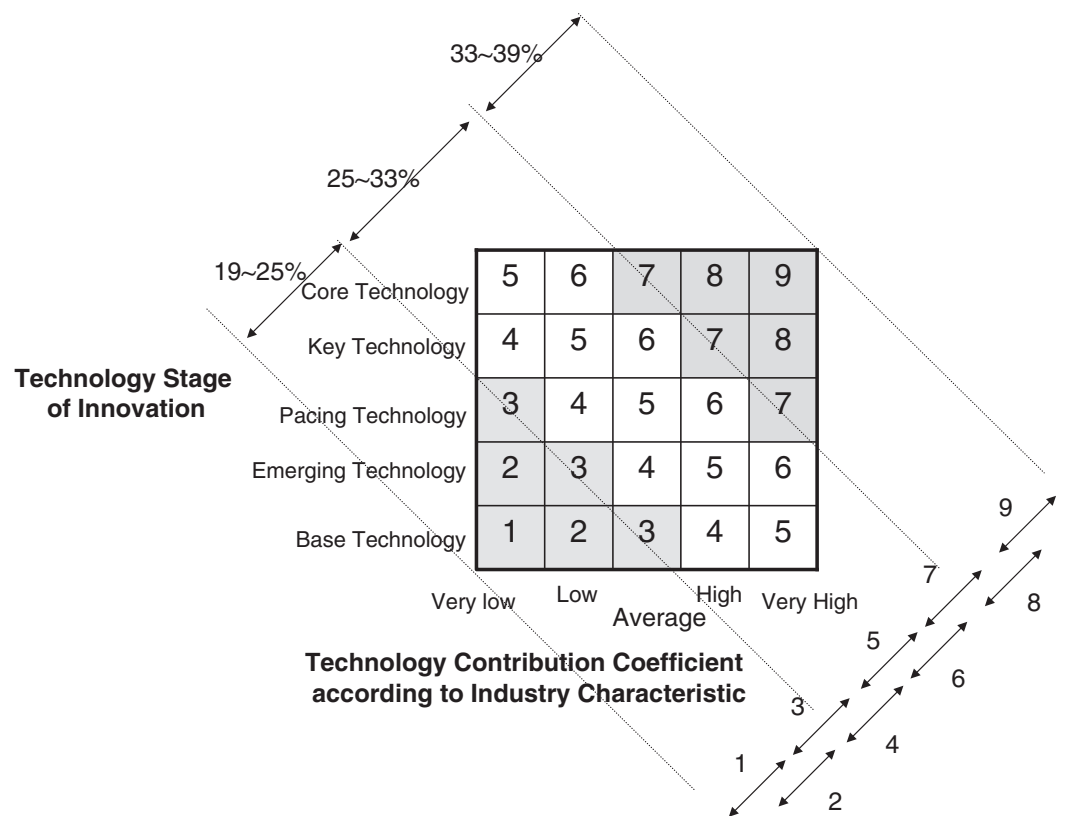

Figure 4. Matrix for technology's degree of contribution.

asset to be around $1 / 4$ to $1 / 3$, this research has also adopted a range of $25-33 \%$ as standard. Because the industry and the characteristic inherent in the technology itself can exert a great influence on technology valuation (Seol, 2000; Yang, 2000), we have constructed a matrix that can adjust the degree of technology contribution according to industry and technology specifics. The matrix in Figure 4 is composed of two dimensions: (1) the importance of intangible asset or technology as a factor of competitive advantage in the industry and (2) the measure of technology's rarity, development potential, and side effect in line with its stage of innovation. Using this matrix, a technology can be classified from the lowest rank (Level 1: low proportion of intangible asset and low rarity in its stage of innovation) to the highest (Level 9: high proportion of intangible asset and very rare in its stage of innovation, while having a great side effect.

After determining the range of degree of contribution in reflection of the industry and technology characteristics, the model calculates the adjustment coefficients to take into consideration technology's dominance, exclusivity, and limitations. The final degree of technology contribution is calculated by reflecting the adjustment coefficient upon the coefficient for degree of technology contribution worked out in the previous step. The degree of technology contribution is used to extract the portion of present value of expected future profits that can be attributed to technology, and this process will allow the objective value of a technology to be evaluated in monetary terms.

Generally, many research and field works concerning technology valuation assumes the degree of contribution of technology assets to be about from $1 / 4$ to $1 / 3$. This is not a logically arrived figure, but rather an assumption that takes into consideration the general practice of identifying intangible assets into three or four types and believes such figure to be reasonable in light of field experience.

Yet as such number is illogical, and as reality dictates that individual categories of intangible assets are not mutually independent, technology valuation becomes difficult and quantifying the valuation even more so (Yang, 2000). According to a study by Lee (1999), technology's degree of contribution is generally determined to be $10 \%$, $25 \%$, and $30 \%$, and this ratio is determined by the evaluation committee according to the technology's field, industry, and characteristics. Moon's (2000) research revealed that the $25 \%$ rule is generally applied in accordance with customary commercial laws, and this method sets the royalty received from using licensed intellectual property to be $25 \%$ of earnings before tax deduction. Hagelin (2004) mentioned that 'The 25 Percent Rule is often claimed to be the most widely used license valuation method.' Goldheim et al.'s (2005) study also suggested that $25 \%$ rule is the hybrid and advanced method that considers additional factors to arrive at a more insightful valuation. 
Thus, the most practical method of estimating the weight of factors that influence technology's degree of contribution would be to rely on qualitative evaluation of professionals who would take into account the characteristic of individual technology and the industry. Yet it is recommended that the Analytic Hierarchy Process be used to increase the degree of confidence by extracting the relative weight of factors influencing technological contribution from many professional groups.

\subsection{Technology valuation from the buyer's perspective}

The objective value of individual technology can become an important reference for technology transfer. However, from the buyer's perspective, the information on the amount of expected earnings in the future may be more important. Individual technology's future profitability can vary according to who owns the technology, and it signifies that the value of technology can change in tune with the owner's capital strength, technology, and human resources. As expected gains from technology can fluctuate depending on the buyer, a technology valuation model that can reflect the uncertain future must be introduced. Thus, the real options model has been added to this purpose.

Various real option models exist by applying the concept of options traded in the financial market to technology valuation, but this research has utilized an altered Black-Scholes option pricing model. Figure 5 depicts changes that have been made to traditional Black-Scholes model to turn it into a real options model. The value of call option in the original model has been changed to the value of technology from the buyer's perspective, the price of the underlying asset into the present value of expected returns from technology, the exercise price into the amounts of investment needed to commercialize the technology, the volatility of the underlying asset into the volatility of expected returns, and the time to maturity into the time period during which commercialization can be attempted without losing rights to the technology.

Black-Scholes option model has been applied in diverse formats in the real option model as it is seen in the studies done by McGrath and MacMillan (2000), Remer et al. (2001). When applying the real options on research and development (R\&D) or project investment, $\mathrm{S}$ usually refers to 'present value of the expected cash inflows from project,' while $X$ indicates 'present value of the expenditures needed to accomplish project' (Remer et al., 2001, p. 99). When applying our model in this perspective, $X$ means 'the additional investment to commercialization' and $S$ refers to 'the present value of expected returns from technology' as the purchaser needs to make investment to commercialize the technology later.

\section{Technology valuation system}

In order for individuals to be able to review quickly and accurately the value of a particular technology by using the technology valuation models explained in Chapter III, a technology

$$
\begin{aligned}
& V=N\left(d_{1}\right) S-N\left(d_{2}\right) X e^{-r T} \\
& \quad d_{1}=\left[\ln (S / X)+\left(r+0.5 \sigma^{2}\right) T\right] / \sigma \sqrt{T} \\
& d_{2}=d_{1}-\sigma \sqrt{T} \\
& V=\text { the value of technology from buyer's position } \\
& S=\text { the present value of expected returns from technology } \\
& X=\text { the additional investment to commercialization } \\
& r=\text { the risk-free rate } \\
& T=\text { the time period for commercialization without losing rights to the technology } \\
& \sigma=\text { the volatility of expected returns from technology } \\
& N(d)=\text { the cumulative normal probability of unit normal variable } d
\end{aligned}
$$

Figure 5. Real options model for technology valuation. 
valuation system that guides them through the process, supplies the necessary data, and calculates the value of the technology according to the value assessment formula within the assessment model needs to be developed. To achieve this goal, through this research, a web-based technology valuation system was created that can be used by technology suppliers, technology buyers, those wanting technology development, and those able to develop new technologies. Under this system, the user will able to assess technologies constantly, rapidly, and efficiently, and therefore this system will contribute to the acceleration of technology transfer, proliferation, and commercialization.

This system will be available for use on the webpage of Korea Institute of Science and Technology Information (KISTI) at 'http://www. itechvalue.org' by accessing it using your web browser. On the upper section of the webpage, there is a 'Technology Valuation' menu, and it is divided into general and professional use. You can access the general use section if you complete user registration, and you have to register as a professional in order to use the professional section.

Once you sign in, the technology valuation starts with 'User Information Entry' and 'Technology Outline Input.' At 'User Information Entry,' there is room to fill in various information such as the name of the user, his/her affiliated organization, contact information, and the purpose of technology valuation. For 'Technology Outline Input,' the user fills in the name of the technology and an explanation of the technology. If it is a patented technology, and the user enters the patent application number, the patent database transmits to the system pertinent information such as the IPC classification, the application date, the name of the applicant, and the name of the inventor.

Using the technology valuation system developed in this study, value of more than 30 technologies has been estimated. So we would like to explain the function and analysis process of the technology evaluation system with one example. The case mentioned here in this study is the personal network storage device for a Korean venture firm, M. As technology that has something to do with the network storage device, this technology links the physical network device to a hard disk driver, and files can be shared between different types of machines by installing an Internet file system in a way that it allows the storing and sharing of the files by making access to the window system. This is an actual case to which the methodology presented in the study has been applied in order to estimate the value of the technology of a network storing device before technology transfer or granting loans for the technology.

\subsection{Analysis of expected returns}

When considering the market size created by a peculiar technology and its cost of production, expected returns analysis is a process in deciding its estimated profit potentials. The steps of the expected returns analysis are Entering the profit generation period and the type of technology Estimating the market size Estimating the cost structure Estimating the present value of expected returns.

\subsubsection{Entry of profit generation period and the type of technology}

The user enters the profit generation period and the type of technology using the same screen as shown in Figure 6. The profit generation period is the number of years during which excess profit can continue to be created by the pertaining technology. It is not an easy task estimating the period of profit generation; however, a rational estimation is possible by analysing the current situation in the industry and the market outlook. Hong et al. (2001) states several useful methods in estimating this period. For the manufacturing industry, this term is usually under 5 years, and according to an analysis of contract period of Korea's international technology transfer, this term is usually between 3 and 7 years. It can be helpful to refer to these data when determining the profit generation period.

Estimating the profit generation period of an individual technology is a very complicated process, and it is nearly impossible to attain a degree of confidence. Therefore, such estimation tends to depend on the subjective judgement of the developer or the owner of technology. It is possible, however, to indirectly estimate the profit generation period of a similar technology by using the Bibliometrics method for instance, a measure that makes use of patents information. Should the technology in question be registered with the US patents office, its technology life cycle can be predicted by analysing the number of times it has been referenced by other technologies. One may also estimate the technology life cycle by applying this analysis of reference frequency to 


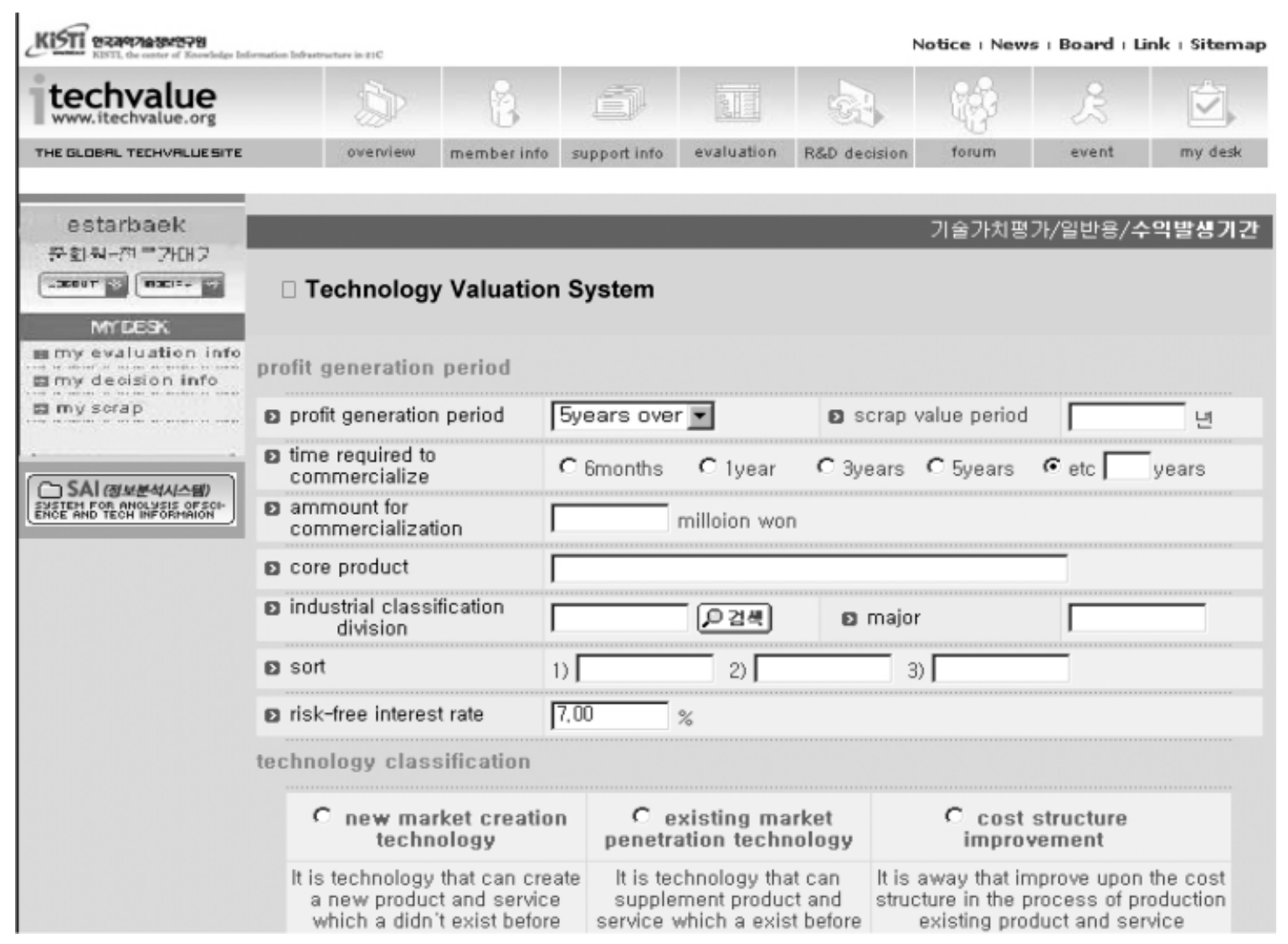

Figure 6. Profit generation period and technology classification.

similar patent technologies or those belonging to related technology group. The performance of research and development activities can be assessed through the reference frequency method relying on Bibliometrics (Moed, 1989). Also, by expanding upon previous research, which states that the mapping of research and development areas can be used to grasp dynamic and structural aspects of technology, such as the direction of technological development and infrastructure, the effectiveness of technology can be estimated using the reference frequency, and this information can be used as a complementary resource for estimating the profit generation period (Braam, 1991).

The residual value period refers to the period during which the technology still maintains its residual value after the profit generation period has ended. The time required to commercialize and the amount of required expenses are data used when assessing the value of a technology from the perspective of the buyer. Besides these, the user selects the core product and the industry that relies on the technology. As explained before, risk-free interest rate is used as a discount rate when converting future-expected profit to present value. As shown at the bottom portion of the figure, the user has to choose one of the technology classifications.

\subsubsection{Market size estimation}

In the case of the new market creation technology, a new product market is created based upon the new technology, and therefore the market size must be estimated during the profit generation period. In the case of the existing market penetration technology, the total market size and the market share of the product based on the new technology is estimated during the profit generation period. For the cost structure improvement technology, as the market has been already formed by an existing product, it is relatively an easy task gauging the market size.

The case mentioned in this research is an existing market penetration technology, and therefore the total market size and market share during 4 years of profit generation period have to be inputted. Figure 7 is the result screen after having sized up the market size, and therefore it 


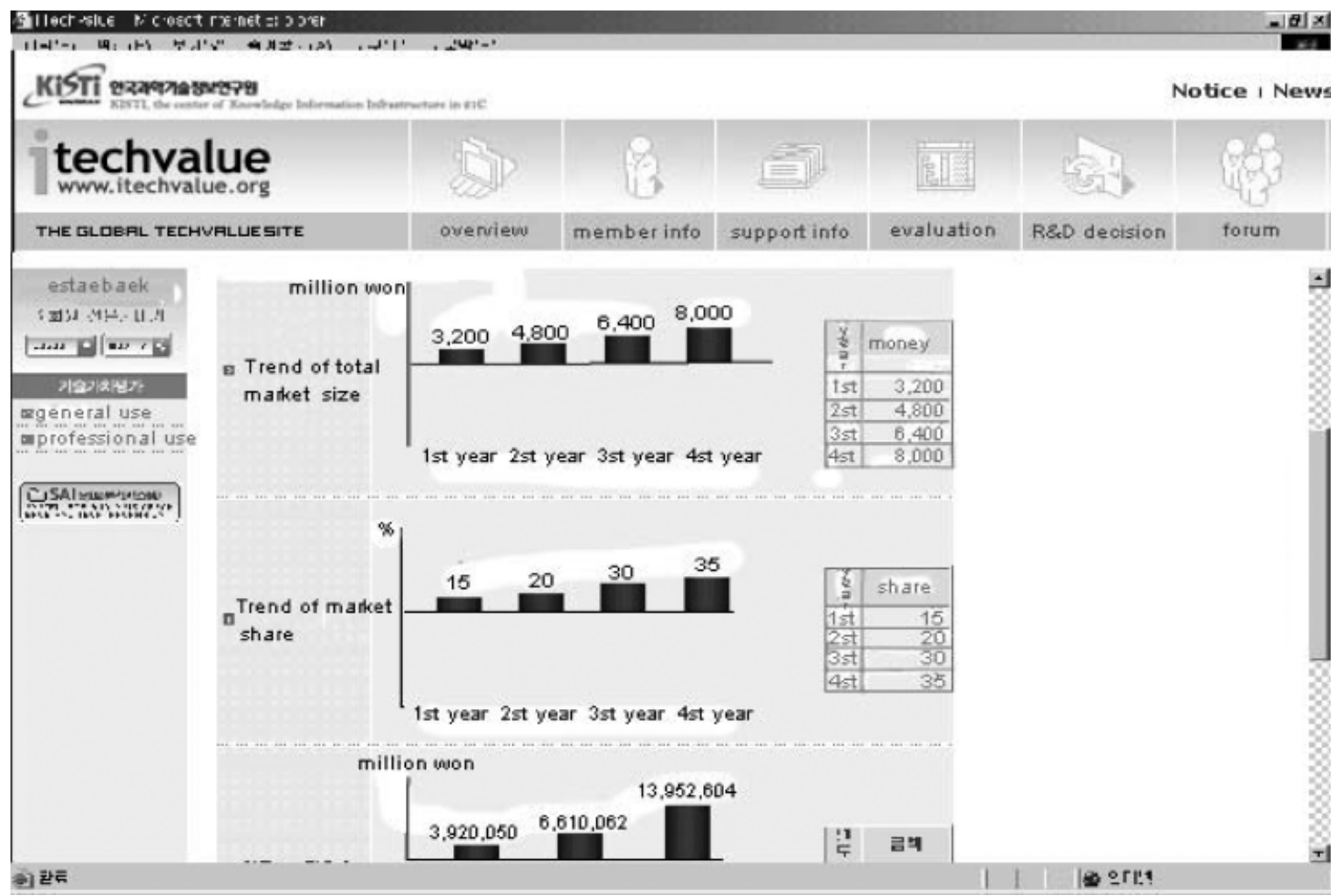

Figure 7. Estimation of market size.

shows the yearly trend of total market size and the market share of the technology. Though it is not shown in the figure, annual data on the market size and the growth rate of the industry, to which the technology's product belongs to, is actually shown at the bottom part of the page and can be very helpful. This page is designed so that the data can be extracted and attached as a reference to support any assessments.

\subsubsection{Cost structure estimation}

This is step for indirectly estimating the cost structure by estimating operations profitability during the profit generation period. There is an input window for entering the rate of operating income during 4 years of profit generation. To assist in gauging the rate, this system provides the average industry rate of operating income along with the average rate of operating income for companies (the user can select up to three) that are most closely related to the technology under evaluation. In the case of personal network storage device technology, the rate of operating income during the profit generation period has been estimated as $20-25 \%$.

Once the estimation of market size and the rate of operating income for the profit generation period is completed, the annual expected returns is automatically calculated by the formula. Expected returns in this research relied on operating income, and annual expected returns is extracted by multiplying the yearly market size with the rate of operating income.

\subsubsection{Estimating the present value of expected returns}

At this point, the expected returns from technology is converted into present value. This step arises from the need to consider the present value of future profits in order to make a decision about technology transfer. The expected returns is easily converted into present value by using the formula explained in Chapter 3.1. The residual value of technology must also be taken into account to estimate the present value. One must determine whether or not to count the residual value of technology that remains after the profit generation period is over. This is a question that must be answered in consideration of each technology's characteristics, however, this case analyzed the residual value to last for 1 year. Here we assumed the residual value to equal the expected return (on the last year of profit generation period) depreciated at a rate of $50 \%$ each year. In this 
case, the present value is estimated to be $1,667,000,000$ wons with residual value, and $1,184,500,000$ wons without.

\subsection{Analysis of technology's degree of contribution}

The objective of this analysis is to figure out the portion contributed purely by technology to the present value of expected returns calculated in the earlier chapter. The analysis proceeds as follows: Calculating the technology contribution coefficient according to level of innovation and industry characteristic classification Adjusting the technology contribution coefficient Calculation of profit contributed purely by technology.

\subsubsection{Calculation of technology contribution coefficient according to classification of stage of innovation and industry characteristics}

This research applied the stage of innovation and industry characteristics to calculate the technology contribution coefficient. Figure 8 explains the process of calculating the contribution coefficient. This process identifies technology's stage of innovation and industry characteristics, and then utilizes the technology contribution matrix in Figure 4 to determine the ranking of contribution (Levels 1-9) The contribution coefficient for each ranking is not a single value, but it is a range of value where the upper and lower $50 \%$ of the value overlaps with that of adjacent ranks.

Figure 9 portrays the logic behind the process of judging the stage of innovation for the technology under evaluation. According to ADL definitions, the stages in technology life cycle are classified into base technology, emerging technology, pacing technology, and key technology (Burgelman et al., 1988). This classification is a very feasible approach to use when it comes to a consistent classification to determine the life cycle of technologies in the same industry. However, in the area of the technology evaluation, we see fusion technologies across different industries come up quite often and they also have a high economic value. This research added core technology to the technology classification considering technology's potential competitiveness, degree of actualization, extent of proliferation, and effect on other industries. In the system, core technology is very essential in securing competitiveness as it has a quite significant impact on the cost, quality, and function of a product. It is also defined as a technology that has percussion to other industries and high potential for expansion.

A technology is classified into base technology, emerging technology, pacing technology, key technology, and core technology, and in addition, technology's potential competitiveness, degree of actualization, extent of proliferation, and effect on other industries are also evaluated.

Figure 10 is the screen for classification of industry characteristics and technology's level of innovation. Industry characteristics measures the importance of technology as an intangible asset in the industry, and this data can be deduced from the industry average $\mathrm{R} \& \mathrm{D}$ investment ratio (vs. total sales) and the ratio of intangible asset to total sales. Using the KSIC's added value to tangible assets ratio information provided by the Korea National Statistical Office, 99 industries have been divided equally into five groups. The industries were classified according to the size of their added value to intangible assets ratio in the order of very low, low, average, high, and very high. In this case, the classification is automated by entering the industry classification code in Figure 7. Then the user is presented with a set of survey questions whose answer will determine

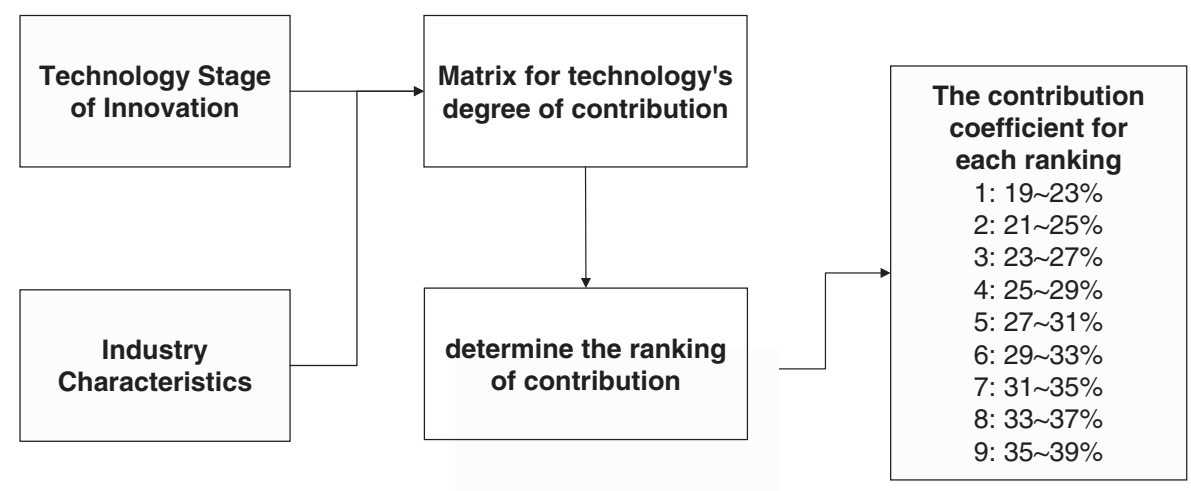

Figure 8. Calculation process for technology contribution coefficient. 


\section{Potential competence}

\begin{tabular}{|c|l|}
\hline Level & \multicolumn{1}{|c|}{ Definition } \\
\hline (1)Basic & $\begin{array}{l}\text { Low level of impact on competency. } \\
\text { Relatively well-known and also commonly } \\
\text { shared. }\end{array}$ \\
\hline $\begin{array}{c}\text { (2) } \\
\text { Emerging }\end{array}$ & $\begin{array}{l}\text { The potential influence on competitive } \\
\text { power is uncertain. }\end{array}$ \\
\hline $\begin{array}{c}\text { (3) } \\
\text { Pacing }\end{array}$ & $\begin{array}{l}\text { The potential value has been proved, } \\
\text { however, it has not been realized by end } \\
\text { product or process. }\end{array}$ \\
\hline $\begin{array}{c}(4) \\
\text { Key }\end{array}$ & $\begin{array}{l}\text { Critical impact on the cost, quality, and } \\
\text { performance of the product. }\end{array}$ \\
\hline (5) & $\begin{array}{l}\text { Critical impact on the cost, quality, and } \\
\text { performance of the product. In addition, it is } \\
\text { extendable to other industries as well. }\end{array}$ \\
\hline
\end{tabular}

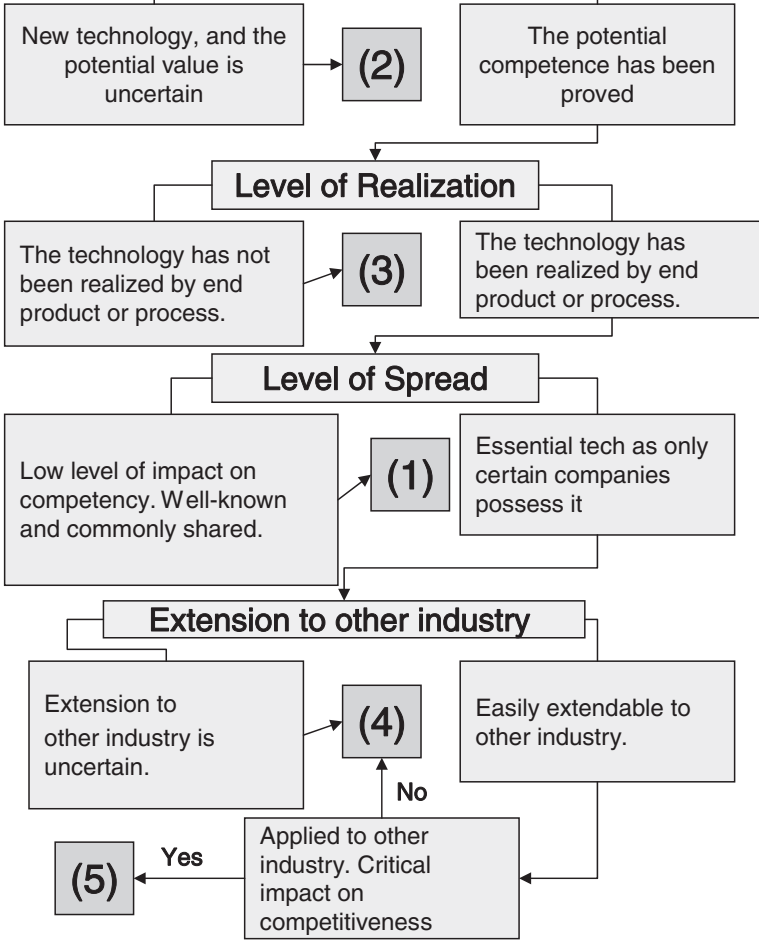

Figure 9. Logics to decide the stage of innovation.

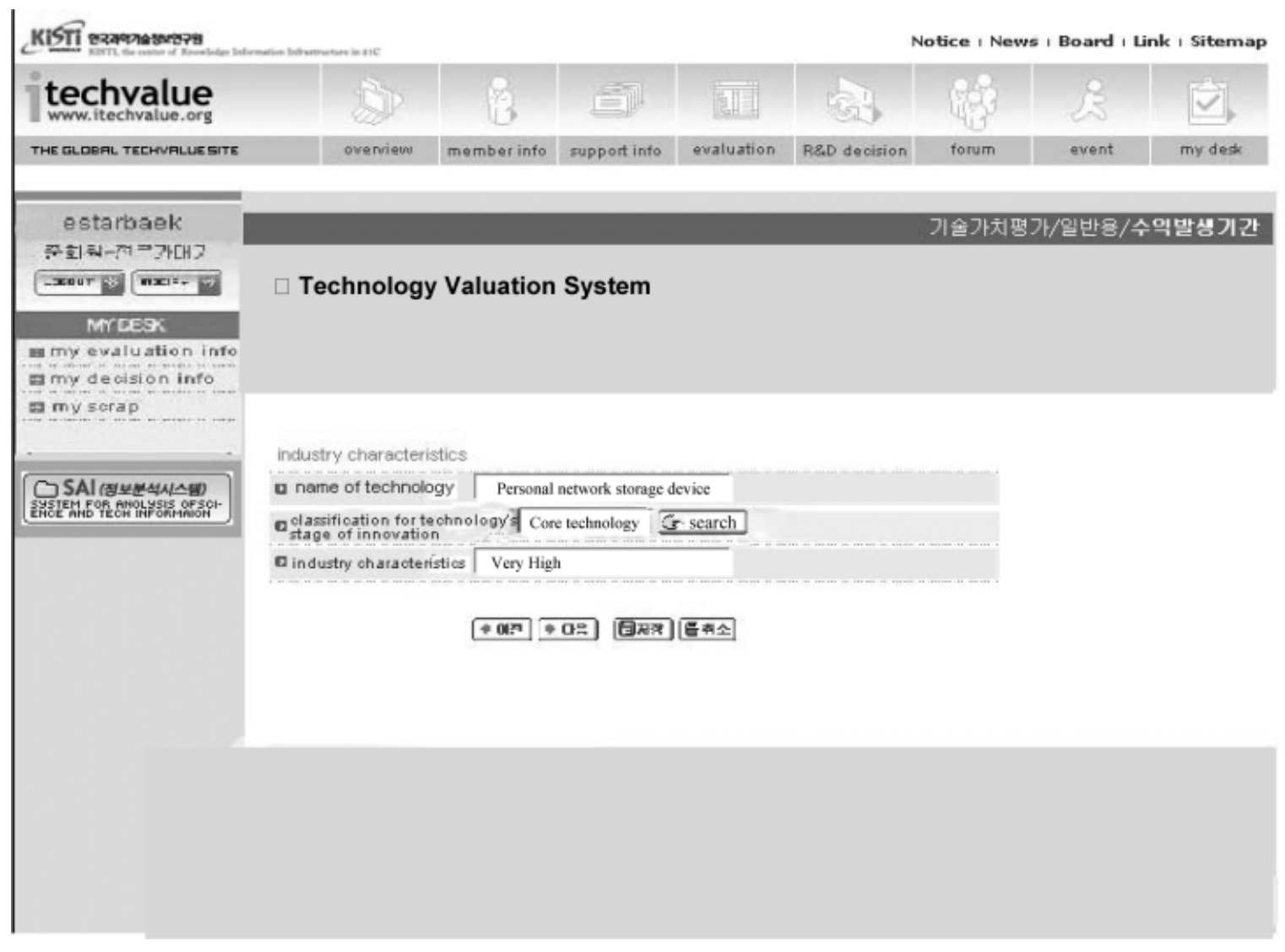

Figure 10. Industry characteristics. 
the technology's stage of innovation. For the case of personal network storage device technology, the level of innovation is 'key technology,' while industrial characteristic is 'very high.' Thus, the technology receives a ranking of Level 8 in the technology contribution matrix, and the range of technology contribution coefficient is $33-37 \%$.

\subsubsection{Adjustment of technology contribution coefficient}

Although there is little doubt that the stage of innovation and industry characteristics are important factors to consider when calculating the technology contribution coefficient, it is also apparent that this coefficient must be adjusted to reflect other factors that influence technology contribution. This research thought it necessary to include technology's dominance, exclusiveness, and limitations.

Technology's dominance refers to the superiority of technology itself and how much of a differentiated value the technology can offer in comparison with other technologies. It also measures technology's applicability and transferability. Technology's exclusiveness deals with whether or not there is any difficulty in exercising the exclusive right to possess and use the technol- ogy and how convenient it is to protect the use of that technology. Finally, technology's limitations are concerned with any competitive or socioeconomic restraints on commercializing and utilizing the given technology.

In order to assess these other factors, the technology valuation system presents a 10-question survey, which the valuator must fill out for each factor using a five-point scale. The results of the questionnaires are used to adjust the technology contribution coefficient, and the range of adjustment has been fixed at $-6-0 \%$. This paper, however, will exclude a detailed explanation on the content of the survey questions and the reasoning behind the adjustment of technology contribution coefficient.

\subsubsection{Calculation of returns contributed by technology}

Figure 11 is a screen displaying the calculated result of returns contributed by technology. The estimated present value and returns attributed to technology are shown for both cases where the residual value is considered and where it is not. As the technology contribution coefficient has a 'range' of values as explained beforehand, the returns contributed by technology is also pre-

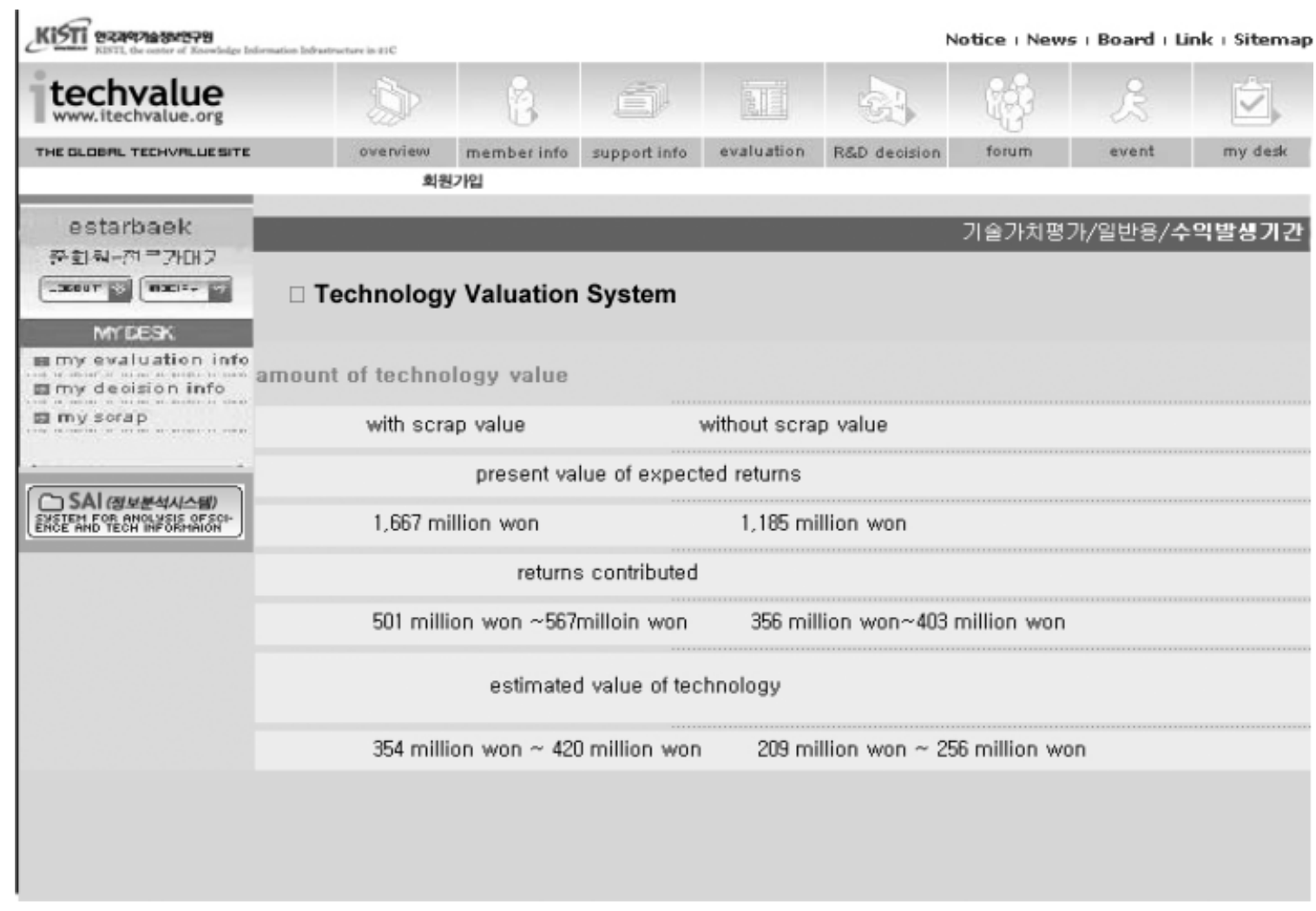

Figure 11. Amount of technology value. 


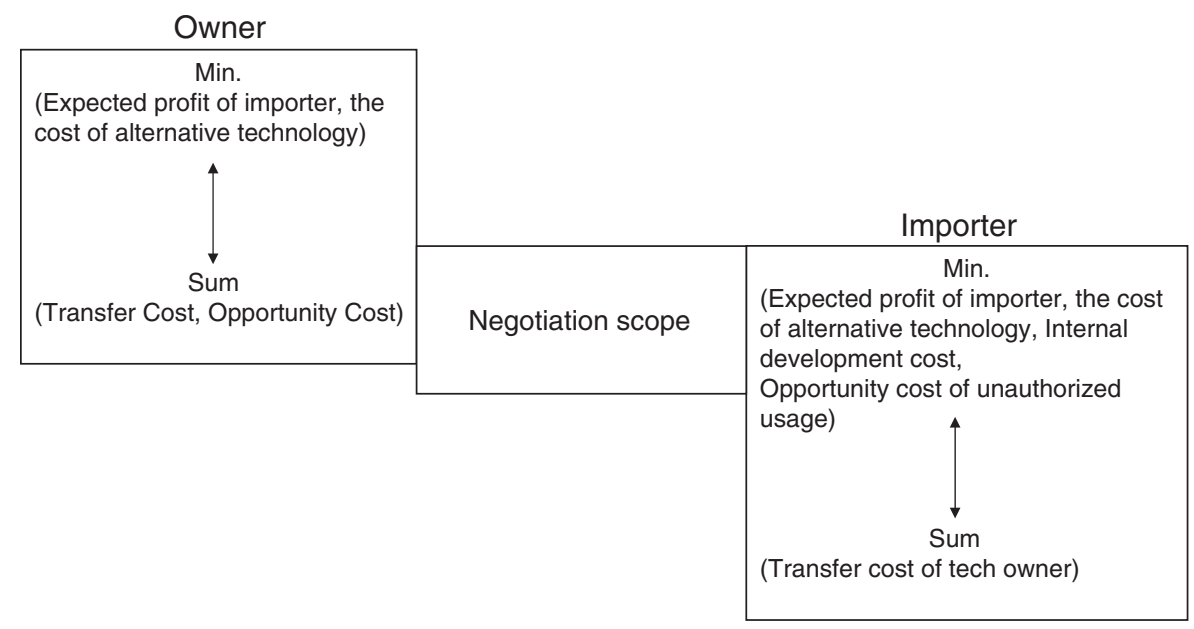

Figure 12. Negotiation model of technology transfer cost between provider and importer.

sented as a range of values. It seems more reasonable to show returns contributed by technology as a range of values rather than a single price. For the personal network storage device technology investigated in this case, the returns contributed by technology with residual value is 501 million $\approx 567$ million wons, while without residual value is 356 million $\approx 403$ million wons.

\subsection{Technology valuation from the buyer's perspective}

The time it takes for commercialization, risk-free interest rate, and the expected returns, which have all been entered in Figure 6, are automatically inserted into the formula explained in Chapter 3.3 to compute the value of technology from the buyer's perspective. The estimated value of technology is listed at the bottom of Figure 11. The value with residual value is 354 million $\approx 420$ million wons, while without residual value is 209 million $\approx 256$ million wons.

The value of technology assessed by our research model is a different concept from the transfer price between buyers and sellers of technology transfer. Transfer price is determined not only by technology value, but by variables such as bargaining power of parties to transaction, uncertainty of commercialization, and the economic outlook. Thus, for an individual company seeking to use this research's valuation model to analyze the price of technology transfer in a negotiation, the technology transfer price negotiation model in
Figure 12 can be used to set a range of possible negotiation for technology price.

\section{Conclusion}

At a period when the national competitiveness increasingly depends on technology, there is an urgent need for technology, in the manner of other goods, to contribute to dissemination of knowledge through active exchanges. In this research, we worked out an objective value of technology, a value that is of utmost importance to vitalizing technology trade and transfer, and attempted to embody this impartial value in a technology valuation system.

Unlike the previous research that mainly assessed technology value from the interest of the holder of technology, this research tried to assay the value of technology from an impartial and objective point of view, and such value can be used as the basic data for technology transfer price negotiations. Also, with the creation of a web-based technology valuation system, both the buyer and the seller can easily measure the value of any technology of interest.

As this research evaluates already fully developed technology for the purpose of transfer, it may not be completely suitable for evaluating technology for public or corporation research and development programs or investment decisions regarding technology development. Having a scientific and well-organized system at the assessment and selection process is necessary to increase the effectiveness and efficiency of research and development programs. For instance, 
many leading nations carry out an economic analysis on proposed projects to create a priority list of research programs. To reflect such demands, the results of this research must not be limited to technology valuation of already completed technology, but must be expanded to become a model to aid in evaluation and selection of research and development programs.

There was one technology that has actually been traded on the Korea Technology Transfer Center out of the ones whose value were evaluated using the Technology Valuation System that we developed. The actual price at which the technology was traded was within the price range that the Technology Valuation System came up with. However, one case is not enough to support that this is superior to alternative or has some objective value. So this is the limit that this study has. In an attempt to overcome this limit, we would like to try the following two approaches. First one is to track the technologies that have actually been traded out of the ones whose value were evaluated using the technology valuation system that we developed so that the values that the system estimated can be compared with the actual values at which they are traded. Second one is to apply the technology valuation system on the technologies that are traded in the technology exchange in order to compare the values that the system came up with and the actual ones. These approaches are expected to allow us to refine the methodologies that we suggested in the study and verify the feasibility and superiority of the methodology suggested in the study.

\section{References}

Boer, F.P. (1999) The Valuation of Technology. New York: John Wiley \& Sons.

Braam, R.R. (1991) Mapping of Science: Foci of Intellectual Interest in Scientific Literature, Ph.D. Thesis, Leiden.

Burgelman, R.A., Kosnik, T.J. and Poel, M. (1988) Toward an innovative capabilities audit framework. In Burgelman, R.A. and Maidique, M.A. (eds), Strategic Management of Technology and Innovation. Homewood, IL: Irwin, pp. 31-44.
Copeland, T. and Antikarov, V. (2001) Real Options: A Practitioner's Guide. London: Texere.

Goldheim, D., Slowinski, G., Daniele, J., Hummel, E. and Tao, J. (2005) Extracting value from intellectual asset. Research Technology Management, 48, 2, 43-48.

Hagelin, T. (2004) Valuation of patent licenses. Texas Intellectual Property Law Journal, 12, 423-441.

Heo, E.N. (2000) Recent developments on economic valuation method: CVA MAUA and ral option pricing. Journal of Korea Technology Innovation Society, 3, 1, 37-54.

Hong, G.P., Kim, H. and Sul, W. (2001) Technology Valuation Model for Technology Transfer, KISTI Research Paper.

Hong, G.P., Kim, H., Sul, W. and Baek, D.H. (2002), Technology Valuation Model for Effective R\&D Investment Decision-makings, KISTI Research Paper.

Lee, J.O. (2001) A comprehensive model of economic valuation for technology. STEPI Journal of Science \& Technology Policy, 11, 2, 21-35.

Lee, S.P. (1999) Valuation Model for Individual Technology, Small and Medium Business Administration Research Paper.

McGrath, R.G. and MacMillan, I.C. (2000) Assessing technology projects using real options reasoning. Research Technology Management, 43, 2, 35-49.

Moed, H.F. (1989) Bibliometric measurement of research performance and Price's theory of differences among the sciences. Scientometrics, 15, 5-6, 473-485.

Moon, Y.H. (2000), How assess the value of technology?, KINITI Research Paper BW112.

Reilly, R.F. and Schweihs, R.P. (1998) Valuing Intangible Assets, McGraw-Hill, New York.

Remer, S., Ang, S.H. and Baden-Fuller, C. (2001) Dealing with uncertainties in the biotechnology industry: the use of real options reasoning. Journal of Commercial Biotechnology, 8, 2, 95-105.

Seol, S.S. (2000) A theoretical framework for the valuation of technology. Journal of Korea Technology Innovation Society, 3, 1, 5-21.

Simon, H.A. (1960) The New Science of Management Decision. New York: Harper and Row.

Smith, G.V. and Parr, R.L. (2000) Valuation of Intellectual Property and Intangible Assets (3rd ed). New York: John Wiley \& Sons.

Yang, D.W. (2000) Valuation for technology on the practical viewpoint. Journal of Korea Technology Innovation Society, 3, 1, 68-84. 